Systematic Literature Review of Art Reception Survey (ARS) on Aesthetic Perception Studies And Future Research Directions

Wan Juliana Emeih Wahed, Saiful Bahari Mohd Yusoff, Noorhayati Saad, Patricia Pawa Pitil

To Link this Article: http://dx.doi.org/10.6007/IJARBSS/v11-i3/8928 DOI:10.6007/IJARBSS/v11-i3/8928

Received: 05 January 2021, Revised: 01 Febuary 2021, Accepted: 25 February 2021

Published Online: 18 March 2021

In-Text Citation: (Wahed et al., 2021)

To Cite this Article: Wahed, W. J. E., Yusoff, S. B. M., Saad, N., \& Pitil, P. P. (2021). Systematic Literature Review of Art Reception Survey (ARS) on Aesthetic Perception Studies And Future Research Directions. International Journal of Academic Research in Business and Social Sciences, 11(3), 997-1008.

Copyright: @ 2021 The Author(s)

Published by Human Resource Management Academic Research Society (www.hrmars.com)

This article is published under the Creative Commons Attribution (CC BY 4.0) license. Anyone may reproduce, distribute, translate and create derivative works of this article (for both commercial and non-commercial purposes), subject to full attribution to the original publication and authors. The full terms of this license may be seen at: http://creativecommons.org/licences/by/4.0/legalcode

Vol. 11, No. 3, 2021, Pg. 997 - 1008

Full Terms \& Conditions of access and use can be found at http://hrmars.com/index.php/pages/detail/publication-ethics 


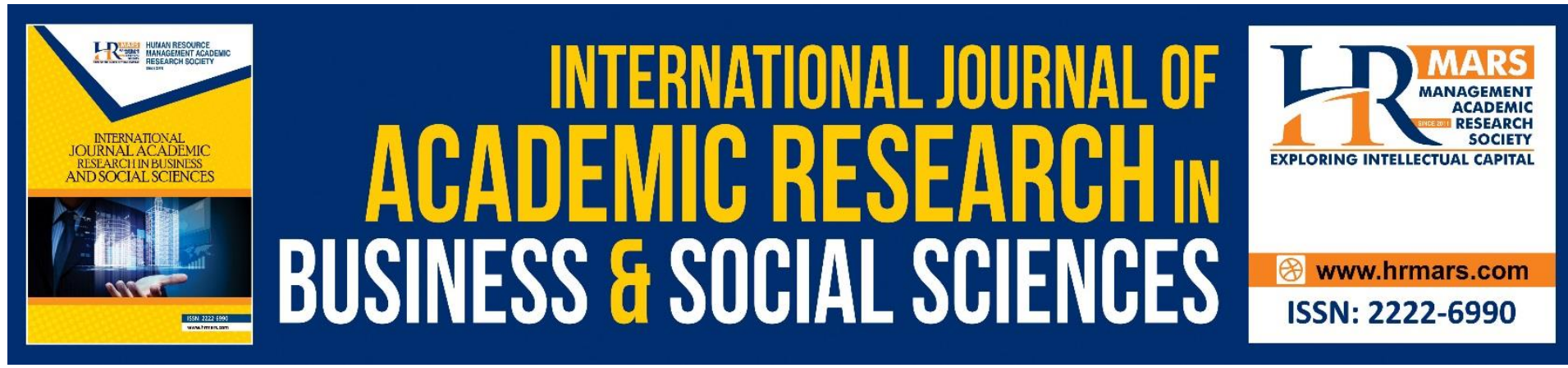

\title{
Systematic Literature Review of Art Reception Survey (ARS) on Aesthetic Perception Studies And Future Research Directions
}

\author{
Wan Juliana Emeih Wahed ${ }^{1}$, Saiful Bahari Mohd Yusoff², \\ Noorhayati Saad ${ }^{3}$, Patricia Pawa Pitil ${ }^{4}$ \\ ${ }^{1}$ Institute of Creative Arts and Technology (iCreaTe), Universiti Malaysia Sarawak
} 94300 Sarawak, Malaysia, ${ }^{1}$ Faculty of Art \& Design, Universiti Teknologi MARA, Cawangan

Sarawak, 94300, Kota Samarahan, Sarawak, Malaysia, ${ }^{2}$ Institute of Creative Arts and Technology (iCreaTe), Universiti Malaysia Sarawak, 94300 Sarawak, Malaysia, ${ }^{3}$ The Design School, Faculty of Innovation \& Technology, Taylor's University, 47500 Selangor Darul Ehsan,

Malaysia, ${ }^{4}$ Universiti Teknologi MARA, Cawangan Sarawak, 94300, Kota Samarahan,

Sarawak, Malaysia

Email:wanjuliana@uitm.edu.my,mysaiful@unimas.my,noorhayati.saad@taylors.edu.my, patriciapawa@uitm.edu.my

\begin{abstract}
Aesthetic studies are engaged with various visual stimuli connected to human senses, which project different perceptions based on one's aesthetic experiences. The right output of the process is a 'symptom' of 'delighted' art which creates positive experiences in measuring a 'good taste' of art. This paper's aim was to review the ARS instrument on different domains of aesthetic studies namely textile, art writing, painting, figurative, abstract painting, representational art and film. The analyses comprised seven adaptations of the Art Reception Survey, indicating the properly designed instrument suited for the screening purposes. The findings demonstrated the influential factors of aesthetics including prior knowledge, art knowledge, familiarity and art connection. The findings also suggested the basis of the instrument adaptation in aesthetic studies, combined with the construction of the understanding between the trained and untrained perceivers.
\end{abstract}

Keywords: Aesthetic, Art Perception, ARS Instrument, SLR, Visual Art.

\section{Introduction}

Aesthetic perception involves the values of the feeling towards any visual arts (Bundgaard et al., 2017) which prompts interest when dealing with the arts. The feeling can either yield beauty, aesthetic interest, or any sort of pleasure. The channel of feeling produced by the perception process can also be translated as appreciative judgment, appraisal, or numerous evaluations and are the basis for the beauty of the art appreciation process.

The aesthetic emergence of human feelings is associated with the process of perception (Scherer, 2020), and when the stimulus is assessed as something that can be 
understood, it becomes human's interest (Silvia, 2005). Meanwhile, human understanding and sensitivity lead to positive perception (Fayn et al., 2018), and by having the right knowledge of a particular subject, one's interest and curiosity can be explored as well as nurtured. It is believed that the aesthetic process happens naturally, as a response to the visual arts, not pre-existed (Xenakis \& Arnellos, 2014).

The mechanisms applied to measuring the aesthetic perception are inter-related with various theories of instrumentation. Art practitioners and researchers have always been intrigued by the studies of aesthetics in various art fields. The growing curiosity has resulted in the establishments of numerous instruments, employed to measure the aesthetic perception and evaluate of the work of art. In regards to the insufficient valid instruments for the assessment of cognitive-affective reactions to aesthetic stimuli (Leder et al., 2004), the Art Reception Survey (Hager et al., 2012) has been customised with the intention of improve the selection of the items. Other than that, the instrument was developed as a response to the limitation of the previous aesthetic experience instrument, Assessment of Aesthetic Perception (SAAP) (Rowold, 2008) and Perception Evaluation instrument (Hagtvedt et al., 2008).

The Art Reception Survey (ARS) instrument was first introduced to measure paintings tallying to six factors; Cognitive stimulation, Negative emotionality, Expertise, Self-reference, Artistic quality and Positive attraction, with a total of 28 items (Hager et al., 2012). It is obvious that every factor appeared in the ARS represents the diversity of measures required for detailed analysing performed by each of the perceivers. In the ARS instrument, cognitive stimulation is the first factor to be measured, implying the reliance of the ability to process cognitive mastering on a person's knowledge. The second factor, negative emotionality or negative emotion or negative effect refers to the experience of receiving negative emotions. The third factor demonstrates the connection of expertise to the level of skills, or knowledge possessed by the perceiver in the context of visual arts. The fourth factor deliberates selfreference as a reference to the individual's tendency to remember or recall information, when information pertaining to visual art is linked to him or her. The artistic quality measures the understanding of originality and technical skills, as well as the last or fifth factor, positive attraction (Hager et al., 2012).

The study's aim is to review the instrument of Art Reception Survey (ARS) in every domain of aesthetic studies. The aim is aligned accordingly with the research question that ponders, "Which of the aesthetic studies employs the Art Reception Survey?". The prior section has enlightened the rationale of performing the systematic review, meanwhile the following section describes the methodology and the PRISMA (Preferred Reporting Item Systematic Reviews and Meta-Analysis) approach adopted by this study. The third section systematically reviews and synthesises the scientific literatures for the purpose of identifying, selecting and appraising relevant researches regarding the aesthetic perception studies. The last section recommends the areas of future research undertakings.

\section{Methodology}

Prisma

The review was guided by the PRISMA Statement (Preferred Reporting Items Systematic reviews and Meta-Analysis) (Moher et al., 2009). 


\section{Resources}

The review was formed based on information collection retrieved from Scopus and Dimensions, as the main journal databases in this study. Scopus is a robust database that offers numerous kinds of literature in different fields of studies. In this study, the data extracted using the related keywords were detected to be more than one thousand peerreview literature. Both databases provided wide-ranging subject areas such as social sciences, psychology and arts, and humanities, in addition to accommodating more than 22,800 journals from more than 5000 publishers.

\section{Eligibility and Exclusion Criteria}

The eligibility and exclusion criterion were determined prior to achieving the principles of the systematic literature review. Initially, the scope of the literature only included journals article, conference proceedings and published theses, while excluding review articles, book series, books and book chapters. Not to mention, the review focused on the articles published in English, implying the exclusion of the articles produced in other foreign languages, in the attempt to avoid misunderstanding in the article translations. Thirdly, the review underwent a four-year period, from 2016 to 2020 which was deemed an adequate length of time (5 years) to examine the evolution of researches and publications. In line with the aim of this study which was to examine the Art Reception Survey (ARS), the review process was grounded to only articles indexed in the social science-based index. Finally, the articles revolving around the aesthetic studies and the ARS instrument were chosen in the interest of being parallel with the objective.

\section{Systematic Review Process}

There were four stages involved in the systematic review process which was performed in May 2020. The first phase was executed by identifying the keywords used in the search process. The search depended on the previous studies and thesaurus where keywords similar to art reception surveys such as 'ARS', 'ARS instrument' were combined with the words related to 'aesthetic', 'aesthetics' and 'aesthetic art' to search string/query string. The result listed 7,540 documents retrieved from the Scopus database within 0.18 seconds of the recorded time. A similar search string was used in the Dimensions database and managed to regain $109,622,324$ documents.

The second stage was then executed by screening the Scopus and Dimensions databases which reduced to only 23 documents, and seven articles eligible for reviewing process respectively. The remaining articles were removed because the standard of the documents clashed with the objective of the study. Not to mention, the requirement for the next stage was limited to articles published in English within the areas of social sciences, arts and humanities and psychology. In the attempt to maximise the screening procedure, the review also omitted the article journal type. The third stage involved eligibility and was conducted by assessing the full articles, of which the careful assessment narrowed down seven articles from Scopus and one article from Dimensions databases for the examination. At this stage of thorough screening, sic duplicated articles, six articles in foreign languages and eight inaccessible articles were removed from the Scopus database. Further reading was conducted on the articles gathered from the Dimensions database which resulted in the removal of one duplicate article, one unrelated topic and two articles in foreign language. 


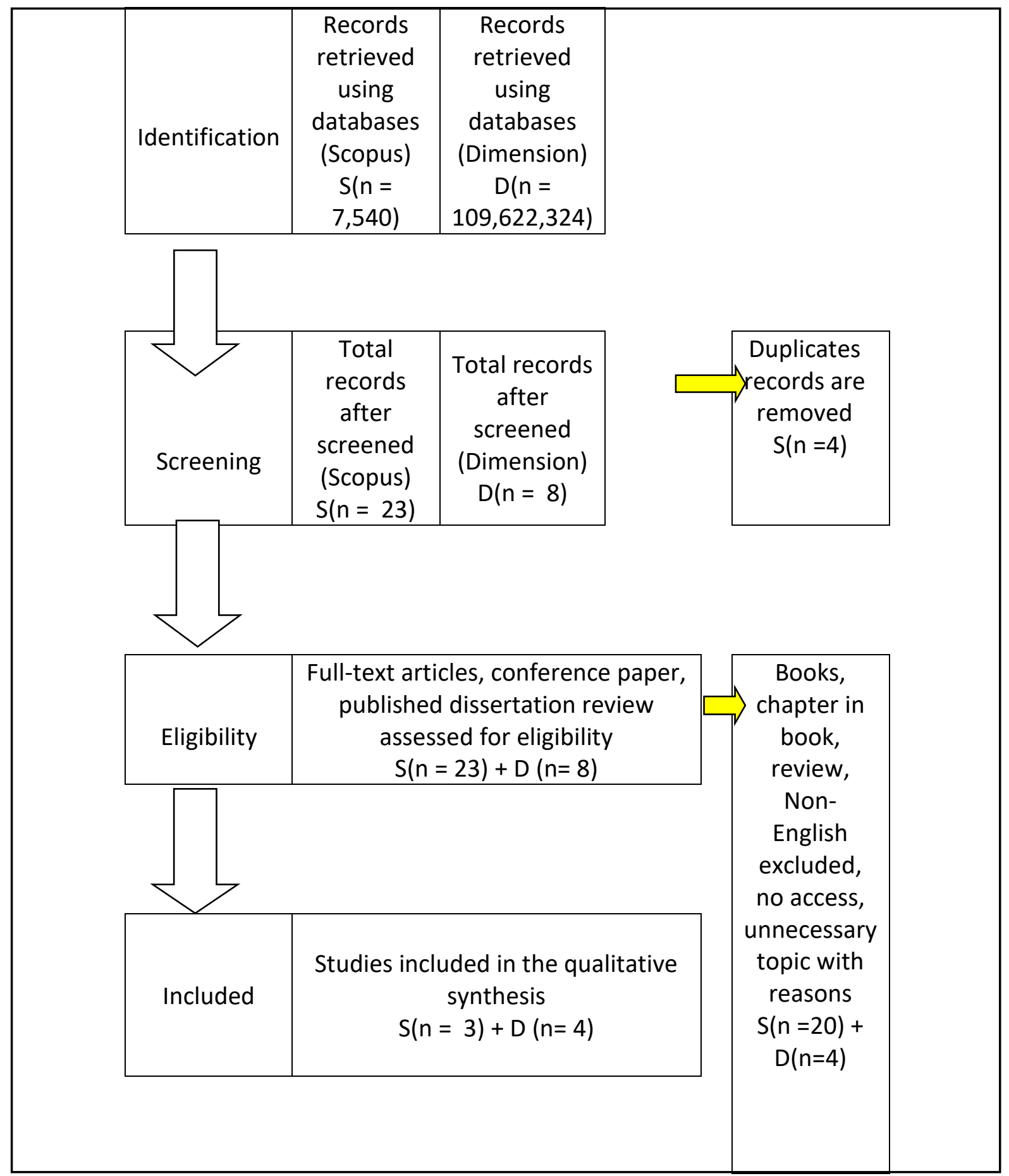

Fig. 1 The Flow Diagram of the Systematic Review

\section{Result}

\section{Study Characteristics}

The review which was extended to seven studies, comprised 1825 multiple respondents of both genders, male and female. As illustrated in Table 4, all of the articles published from 2016 to 2020 were of peer-reviewed journals. The studies were administered in different countries other than Malaysia (Wahed et al., 2020), which were United States (Quiroga, 2020), Germany (Miller \& Hübner, 2019; Pirgie, 2016), Poland (Pietras \& Czernecka, 
2018), Canada (Wang, 2018), and the Netherlands (Doicaru, 2016). Five of the studies targeted students as the main populations (Doicaru, 2016; Miller \& Hübner, 2019; Pietras \& Czernecka, 2018; Pirgie, 2016; Quiroga, 2020), while the other two studies recruited the visitors from the commercial markets and museums (Wahed et al., 2020), along with the online recruitment (Pietras \& Czernecka, 2018). However, there was one study engaged in multiple populations involving university students, online users and the attendees of the International Film Festival in Rotterdam (Doicaru, 2016).

\section{Domains}

In the anticipation of achieving the study's objective, multiple domains were employed and aligned with the suggestion of Hager et. al (2012), that the ARS instrument is beneficial in the various fields of aesthetic research. The review uncovered that various domains have applied the ARS instrument such as textile (Wahed et al., 2020), art writing (Quiroga, 2020), painting (Miller \& Hübner, 2019; Pietras \& Czernecka, 2018; Wang, 2018), film (Doicaru, 2016), figurative (Pietras \& Czernecka, 2018) and abstract art in museums (Pirgie, 2016).

\section{Instruments}

All studies adopted the Art Reception Survey (ARS) instrument with improvised versions in order to answer the objectives of the studies. The study undertaken by Wahed et.al (2020) employed the ARS instrument with 21 items, while one factor was removed; Negative emotionality, 15 items with combination manifold ARS factors (Quiroga, 2020), three items measuring three different factors of Positive Attraction ("this painting is beautiful"), Cognitive Stimulation ("this painting is thought-provoking"), and Negative emotionality ("This painting causes emotions") (Miller \& Hübner, 2019). Moreover, the study implemented 20 items of the ARS instrument with five significant factors and omitted Cognitive stimulation. the(Pietras \& Czernecka, 2018). The other three studies modified the overall ARS instrument with six factors and 28 items (Doicaru, 2016; Pirgie, 2016; Wang, 2018). 
Table 1. Data Extraction Table of Included Studies

\begin{tabular}{|c|c|c|}
\hline Domain & Objective & Main Findings \\
\hline Textile & $\begin{array}{l}\text { Measuring the aesthetic } \\
\text { perceptions about the design } \\
\text { motifs applied on the cloth, } \\
\text { among } 400 \text { respondents } \\
\text { according to their genders and } \\
\text { backgrounds. }\end{array}$ & $\begin{array}{l}\text {-The expertise factor exhibited a } \\
\text { significant difference in the gender and } \\
\text { background of respondents. } \\
\text {-Self-reference and Cognitive } \\
\text { Stimulation exhibited significant } \\
\text { differences in the respondents' } \\
\text { background. }\end{array}$ \\
\hline $\begin{array}{l}\text { Art writing on } \\
\text { fine art }\end{array}$ & $\begin{array}{l}\text {-Exploring how writing on arts } \\
\text { leads to explanatory depth } \\
\text { and affects aesthetic } \\
\text { appreciation. } \\
\text {-Exploring the perceptions } \\
\text { toward the fine arts with how } \\
\text { important people believe the } \\
\text { arts to be. }\end{array}$ & $\begin{array}{l}\text { - The finding shows that engagement in } \\
\text { a writing task increased perception of } \\
\text { the fine arts. } \\
\text { - The fine arts are difficult to define and } \\
\text { measure in psychological research } \\
\text { mainly due to different cultural views } \\
\text { and lack of a definition that is } \\
\text { collectively agreed upon in society. }\end{array}$ \\
\hline Paint & $\begin{array}{l}\text { Investigating to what extent lay } \\
\text { people can infer the aesthetic } \\
\text { preferences of others. }\end{array}$ & $\begin{array}{l}\text { - The finding shows that laypeople rely } \\
\text { more on their affective states when } \\
\text { judging aesthetic stimuli compared } \\
\text { with art experts. }\end{array}$ \\
\hline $\begin{array}{r}\text { Figura } \\
\text { abstra } \\
\text { contem } \\
\text { pain }\end{array}$ & $\begin{array}{l}\text { Investigating the predictors of } \\
\text { aesthetic experiences across } \\
\text { figurative, abstract and } \\
\text { contemporary paintings in } \\
\text { individuals with varying } \\
\text { expertise. }\end{array}$ & $\begin{array}{l}\text { - Students with art - experience (Art } \\
\text { students) influenced art reception. } \\
\text { - Art students perceived aesthetics } \\
\text { greater compare to other two groups. }\end{array}$ \\
\hline $\begin{array}{c}\text { Abstract } \\
\text { painting and } \\
\text { Representatio } \\
\text { nal art }\end{array}$ & $\begin{array}{l}\text { Assessing the familiarity of the } \\
\text { self -relevant with the selected } \\
\text { painting, and not on a } \\
\text { comparison of aesthetic } \\
\text { appreciation of paintings. }\end{array}$ & $\begin{array}{l}\text { as screening purposes } \\
\text {, the other factors in } \\
\text { sed. }\end{array}$ \\
\hline Abs & $\begin{array}{l}\text { Investigate possible differences } \\
\text { in the perception of genuine } \\
\text { and original artworks } \\
\text { compared to reproductions } \\
\text { and non-artworks. }\end{array}$ & $\begin{array}{l}\text { - No significant difference could be } \\
\text { observed between the original and } \\
\text { reproduced. } \\
\text { - Original artworks were judged as } \\
\text { significantly more interesting than } \\
\text { computer images } \\
\text {-Negative emotionality was rated as the } \\
\text { least in the original art condition }\end{array}$ \\
\hline Гाіा & $\begin{array}{l}\text { Developing an instrument to } \\
\text { measuring the aesthetic } \\
\text { appreciation of film, The Scale } \\
\text { of Aesthetic Appreciation of } \\
\text { Film (SAAF). }\end{array}$ & $\begin{array}{l}\text { The used of the ARS in this study is to } \\
\text { permitted the researcher in developing } \\
\text { an instrument to measure the aesthetic } \\
\text { appreciation of film. }\end{array}$ \\
\hline
\end{tabular}




\section{Main Findings}

In reiteration, the Art Reception Survey (ARS) instrument has been positively remodelled to be equivalent to the domain's congruency; Textile, with the deletion of the Negative Emotionality factor. The Art Reception Survey-Revised (ARS-Revised) (Wahed et al., 2020) was distributed to 400 respondents who visited the Waterfront Kuching, Tun Jugah Foundation and Sarawak Textile Museum located in the Borneo part of Malaysia, Sarawak. The study disclosed interesting findings in regards to the Expertise, Self-reference and Cognitive Stimulation factors which exhibited a significant difference in the genders and backgrounds of the respondents. The art knowledge of the Sarawak respondents about the domain of the study, 'textile', or specifically the intangible cultural heritage of Sarawak Iban Pua Kumbu, was higher in Cognitive Stimulation, indicating the commendable awareness possessed by the Sarawak respondents, who seemed to be more familiar with the textile compared to other races in Malaysia. Aside from that, the study also revealed a significant influence of art knowledge on the genders and backgrounds of the respondents in appreciating aesthetic at its best (Wahed et al., 2020).

The comparable findings in were then discovered, highlighting the significance of the prior art knowledge in aesthetic studies (Pietras \& Czernecka, 2018). The study was conducted on 181 Polish students ( $\mathrm{N}-181$ ) who enrolled in various programmes; Sport, Humanities and the Arts programmes from the Pedagogical University of Cracow as well as the University of Physical Education in Cracow, Poland. The Art Reception Survey (ARS) instrument (Hager et al., 2012) was modified through the employment of only 20 items instead of 28 items from the original version in measuring the students' aesthetic experiences across figurative, abstract and contemporary paintings. The findings revealed that the Art students grasped clearer understanding of the aesthetic, as opposed to other non-art groups; Sports and Humanities.

Next, Miller et al. (2019) distributed the ARS instrument which consisted of only three items measuring three different factors of the Art Reception Survey, namely Positive Attraction ("This painting is beautiful"), Cognitive Stimulation ("This painting is thoughtprovoking"), and Negative emotionality ("This painting causes emotions"), to 40 students of University of Konstanz ( $\mathrm{N}=40)$ using the online form study design. The study focused on understanding the aesthetic preferences towards the domain subject; painting among the untrained and lay-people. The result suggested the art experts were able to form aesthetic perceptions better than lay-people, depending on their affective states (Miller \& Hübner, 2019). Knowingly, the way humans appreciate something is different from one another, as it is usually based on how they see and react towards the subject. Silvia (2005) agreed that people display different emotional appraisals towards art and it makes visual art interesting. Therefore, the distinction between untrained and trained viewers creates a gap in evaluating and criticising a work of art, which also depends on the level of art appreciation possessed by a person (Silvia, 2005).

Quiroga (2020) improvised the ARS instrument by assessing the implication of fine arts writing towards aesthetic perception. Using the convenient sampling technique, the undergraduate students recruited from Texas Woman's University in North Texas were selected as the population of this study $(\mathrm{N}=397)$. A total of 15 items was administered and the result detected an increase in the respondents' art perception towards fine arts through the engagement of the writing task. The relation between fine arts in measuring the respondents' psychological being seemed difficult due to the confined cultural perspective 
and insufficient collective agreement regarding the art definition among society (Quiroga, 2020).

Meanwhile, another study demonstrated a different idea of implementing the ARS which was through familiarisation with the self-relevance of the painting (Wang, 2018). The author adopted the ARS instrument with the exact total of six factors and 28 items without removing any of it. Using a simple random sampling technique, the survey was distributed online on the MTurk website to 360 respondents $(\mathrm{N}=360)$. The use of ARS in the study acted as a screening purpose, which focused only on two factors in the questionnaire; self-reference and expertise without further elaboration on the other factors (Wang, 2018). Another study by Pirgie (2016) generated an idea of re-creating the museum in exploring the perceivers' art perceptions of the genuine and original artworks compared to reproductions and nonartworks. The abstract art in the museum was selected as the domain of the study with a population of 91 students of the University of Vienna ( $\mathrm{N}=91)$. Using the convenient sampling technique, the Art Reception Survey (ARS) instrument was distributed to the respondents who were divided into three groups; Original Art $(n=30)$, the Reproduction $(n=31)$ and the Non-Art $(n=30)$. A total of 28 items of the ARS with six factors was employed in the study. The ARS instrument displayed a significantly reliable method to measure respondents' connectedness with an artist, and by extension, an artwork. The findings suggested that the original artwork was more pleasing rather than slides or computer images, and the Negative emotionality factor was rated the lowest in the original art (Pirgie, 2016).

Furthermore, Doicaru (2016)'s study identified that Art Reception Survey (ARS) was used in developing a new instrument of measuring the aesthetic appreciation of film; Scale of Aesthetic Appreciation of Film (SAAF). A total of 322 students from the University of Amsterdam, nine from an experimental film at the Eye Film Institute in Amsterdam, 18 Facebook 'arthouses' and seven from the International Film Festival in Rotterdam were selected as the respondents through a random sampling technique ( $N=356)$. One-way repeated measure design was used in this experimental study. The original of 28 items of the Art Reception Survey (ARS) instrument with six factors were utilised in the study, with the addition of two more items inserted by the researcher. The literal reproduction from the ARS instrument was the change of the word "painting" to "film".

Overall, the findings suggested that there is a demand for studies on assessing the aesthetic of visual arts by using the ARS instrument, with the addition of the fluency of aesthetic perception and experiences.

\section{Discussions}

The Art Reception Survey (ARS) is widely applicable in any domain of aesthetic studies. It has been proven by the systematic literature review conducted in this study which was represented by a variety of domains in aesthetic studies. Nonetheless, some studies implemented the ARS instrument as the initial or screening purpose before proceeding to the new-fangled instruments or studies (Doicaru, 2016; Wang, 2018). The fluency of aesthetic evaluation was incorporated with the factors of confirming the effectiveness of conducting aesthetic studies. Based on the analysis conducted on the literature review, several aspects which encouraged the fluency of the aesthetic process were identified to be prior knowledge (Pietras \& Czernecka, 2018; Wahed et al., 2020), art knowledge (Miller \& Hübner, 2019; Wahed et al., 2020), the familiarity of the elements applied in the visual arts (Wahed et al., 2020; Wang, 2018) and the connection between art-artist-perceivers (Pirgie, 2016). 
According to Berlyn's study $(1970,1971)$, the more people have experience or prior knowledge, either directly or indirectly, the more perceptions can be established. Knowing before the subject eases the acquisition and the transfer of the relevant evaluation as well as perception. Besides, the prior knowledge received regarding the historical perspective as well as the artist's life story can increase the understanding of the contextual meaning possessed by every visual art (Cupchik et al., 2009; Nodine et al., 2008). Other factors such as experience (Grüner et al., 2019) and art genuineness (Benjamin \& Jennings, 2010) keep the perceiver's aesthetic experience increased and grown, not solely because of the visual arts.

Bourdieu (1979) conducted a study on the aesthetic perception stimuli of the art knowledge among museum visitors to gather their experiences regarding the exhibited visual arts. As an art sociologist, Bourdieu believed that every art carries an unspoken message or code, which could be deciphered and comprehended (Bourdieu, 1979). The author defined this aesthetic activity as "educated taste", which allows the perceivers to have full of 'authority' to feel the art's 'flavour' (Bourdieu, 1979). Relatively, the connection between visual art and art knowledge is vital in performing aesthetic studies.

Furthermore, the adaptation and the familiarisation of the perceivers towards any environment of the culture were discovered to enhance their aesthetic understanding and knowledge (Yang et al., 2019). In other words, if the perceivers lack information regarding the input retrieved, the aesthetic experiences will be distracted, as they are understood differently in different cultures. Zeki (2011) added, the great visual art can distribute its messages and contents to all perceivers without boundaries in every historical time frame. It can be proclaimed that the artist also plays an important role to transfer the message or knowledge to the perceivers efficiently, which can result in the correct form of perception among the perceivers (Zeki, 2011).

\section{Conclusion}

In all the studies included here, the participants were mainly students, with a large range of ages, and mostly from the western countries. This prevents a generalisation of these findings on a wider population. Future studies are recommended to conduct a comparison in the fields of aesthetics between foreigners or visitors with the locals. It is believed that comparative studies can broaden the aesthetic evaluation scope thus contribute to new and different, yet interesting findings. In conclusion, this systematic review emphasised that Art Reception Survey (ARS) was appropriate to be used in any aesthetic studies using any category of research design, sampling technique and population. The findings of the ARS instrument in this study helped boost the perceivers' understanding and at the same time, assisted the researcher in categorising the trained and untrained perceivers. It was discernible in this study that trained perceivers had a better assessment of visual art compared to untrained perceivers, who needed more time to understand, evaluate and form opinions due to lack of experience and exposure.

\section{Acknowledgements}

The researchers have no conflict of interest.

\section{References}

Benjamin, W., \& Jennings, M. W. (2010). The work of art in the age of its technological reproducibility [first version]. Grey Room, 11-37.

Bourdieu, P. (1979). Symbolic power. Critique of anthropology, 4(13-14), 77-85. 
Bundgaard, P. F., Heath, J., \& Østergaard, S. (2017). Aesthetic perception, attention, and nongenericity: How artists exploit the automatisms of perception to construct meaning in vision. . Cognitive Semiotics, 10(2), 91-120.

Cupchik, G. C., Vartanian, O., Crawley, A., \& Mikulis, D. J. (2009). Viewing artworks: contributions of cognitive control and perceptual facilitation to aesthetic experience. Brain and cognition, 70(1), 84-91.

Doicaru, M. M. (2016). Gripped by movies: From story-world to artifact absorption. Unpublished doctoral dissertation). University of Amsterdam.

Fayn, K., Silvia, P. J., Erbas, Y., Tiliopoulos, N., \& Kuppens, P. (2018). Nuanced aesthetic emotions: Emotion differentiation is related to knowledge of the arts and curiosity. Cognition and Emotion, 32(3), 593-599.

Grüner, S., Specker, E., \& Leder, H. (2019). Effects of context and genuineness in the experience of art. Empirical Studies of the Arts, 37(2), 138-152.

Hager, M., Hagemann, D., Danner, D., \& Schankin, A. (2012). Assessing aesthetic appreciation of visual artworks-The construction of the Art Reception Survey (ARS). Psychology of Aesthetics, Creativity, and the Arts, 6(4), 320.

Hagtvedt, H., Patrick, V. M., \& Hagtvedt, R. (2008). The perception and evaluation of visual art. Empirical studies of the arts, 26(2), 197-218.

Leder, H., Belke, B., Oeberst, A., \& Augustin, D. (2004). A model of aesthetic appreciation and aesthetic judgments. British journal of psychology, 95(4), 489-508.

Miller, C. A., \& Hübner, R. (2019). Two routes to aesthetic preference, one route to aesthetic inference. Psychology of Aesthetics, Creativity, and the Arts. https://doi.org/https://doi.org/10.1037/aca0000241

Moher, D., Liberati, A., Tetzlaff, J., Altman, D. G., \& Group, P. (2009). Preferred reporting items for systematic reviews and meta-analyses: the PRISMA statement. PLoS med, 6(7), e1000097.

Nodine, C., Mello-Thoms, C., Krupinski, E., \& Locher, P. (2008). Visual interest in pictorial art during an aesthetic experience. Spatial vision, 21(1-2), 55-77.

Pietras, K., \& Czernecka, K. (2018). Art training and personality traits as predictors of aesthetic experience of different art styles among Polish students. Polish Psychological Bulletin, 49(4), 466-474.

Pirgie, L. S. (2016). Lost in contemplation of original artworks uniwien]. http://othes.univie.ac.at/41782/

Quiroga, M. (2020). Social desirability, need for uniqueness, and the illusion of explanatory depth in perceptions of the fine arts

Rowold, J. (2008). Instrument development for esthetic perception assessment. Journal of Media Psychology, 20(1), 35-40.

Scherer, K. R. (2020). Evidence for the existence of emotion dispositions and the effects of appraisal bias. Emotion.

Silvia, P. J. (2005). What is interesting? Exploring the appraisal structure of interest. Emotion, $5(1), 89$.

Wahed, W. J. E., Saad, N., \& Yusoff, M. S. B. (2020). Sarawak Pua Kumbu: aesthetics lies in the eye of the beholder. In press.

Wang, W. (2018). Narcissistic Intolerance: Verbal Hostility and Dismissiveness in Response to Subjective Disagreement.

Xenakis, I., \& Arnellos, A. (2014). Aesthetic perception and its minimal content: a naturalistic perspective. Frontiers in psychology, 5, 1038. 
Yang, T., Silveira, S., Paolini, M., Pöppel, E., Sander, T., \& Bao, Y. (2019). Aesthetic experiences across cultures: neural correlates when viewing traditional Eastern or Western landscape paintings. Frontiers in psychology, 10, 798.

Zeki, S. (2011). Splendors and miseries of the brain: Love, creativity, and the quest for human happiness. John Wiley \& Sons. 